\title{
Editorial: Starting Volume Twelve, Celebrating the Twelfth Year of Platinum Open-Access
}

\author{
Alexandru Mihai Grumezescu 1,2,* (D) \\ 1 Department of Science and Engineering of Oxide Materials and Nanomaterials, Faculty of Applied Chemistry and \\ Materials Science, University Politehnica of Bucharest, Romania \\ 2 Research Institute of the University of Bucharest (ICUB), University of Bucharest, Romania \\ * Correspondence: agrumezescu@upb.ro;
}

Received: 12.04.2021; Revised: 15.04.2021; Accepted: 17.04.2021; Published: 19.04.2021

Dear Readers, Authors, Reviewers, and Editorial Board Members,

Gratitude for the continuous support of the Biointerface Research in Applied Chemistry. Volume eleven (associated to 2021) contains 600 papers, which cumulates 7784 pages, which means five times more pages than volume ten (associated to 2020). This was possible thanks to the trust that all of you have in this journal. All papers accepted in this journal are published under the platinum open-access policy, which means that no fees have to be paid by the authors and $100 \%$ permanent free access for authors and readers.

I would like to share a recently published paper highlighting the first bibliometric analysis of Biointerface Research in Applied Chemistry from 2016 to 2020: https://doi.org/10.33263/BRIAC116.1507515140. I am thrilled to conclude that 838 research institutes from 77 countries have participated in fulfilling the journal's focus.

You are very welcome to submit your next manuscript, either original research or review paper, to be considered for publication Biointerface Research in Applied Chemistry.

Keywords: applied chemistry; biointerface research; chemical engineering; biochemistry; nanochemistry.

(C) 2021 by the authors. This article is an open-access article distributed under the terms and conditions of the Creative Commons Attribution (CC BY) license (https://creativecommons.org/licenses/by/4.0/). 